\title{
Cutting the network? Facebook's Libra currency as a problem of organisation
}

\author{
Daniel Tischer \\ University of Bristol, UK
}

\begin{abstract}
This essay explores the organisational character of Facebook's Libra currency by undertaking a critical reading of documents published by the Libra Association. Drawing on the conceptual work of Marilyn Strathern and Michel Serres, it illustrates how ownership cuts the network and encourages parasitism as a means of driving future profit. Central to this is the claim that Libra is not an exercise in democratising money, but rather, the opposite: Libra is run as a club, for the benefit of club members. The conceptual theme of 'cutting' is used to organise the argument. Rather than a cutting-edge technology, Libra's true innovation is organisational and consists in overturning the decentralised character of blockchain, such that distributed ledger technology is re-centralised by big tech firms. Outsiders are thus cut-off from Libra; only those inside the club have the right to participate in Libra and its governance. This position also affords members an exclusive capacity to take a cut of the profits generated through Libra. As a private organisation, members have sole rights to future profits generated from the Libra ecosystem and are in this way incentivised to create new product opportunities over time.
\end{abstract}

\section{Keywords}

Facebook, Libra, digital payments, cryptocurrencies, organisation, club, network

\section{Introduction}

Facebook's announcement of the Libra in June 2019 was an important step for digital currencies. Not only was it the first such initiative launched by a major global tech company; it was also presented as a break with the major cryptocurrencies. Libra was and remains a proposal for a small-'c' cryptocurrency to address the problems of volatility and scalability experienced by big- 'C' cryptos. It was devised to "reach mainstream adoption" (LWP, 2019a).

\section{Corresponding author:}

Daniel Tischer, Department of Management, University of Bristol, 2.06 Howard House, Queen's Avenue, Bristol BS8 1SD, UK. Email: daniel.tischer@bristol.ac.uk. https://doi.org/10.2218/finsoc.v6i1.4406 
Dubbed by some 'Facebook's Bitcoin', its promoters promise it will become a global currency, permitting frictionless transactions and bringing electronic payments to the 1.7 billion people who currently lack access to basic digital financial services. It will be inexpensive; it will be accessible to all; and it will be delivered to the world's masses responsibly, universalising the ability for people around the world to make choices in payment and finance that will empower them.

The timing of the announcement situates Libra in a peculiar post-boom crypto-period. The launch of Bitcoin in 2009 generated substantial interest in cryptocurrencies within the investment community and amongst a broader public audience, sustained by the launch of evermore new currencies alongside ever-inflating asset values. Academic discussion quickly developed along the lines laid out by disciplinary boundaries. Information systems focused on conceptual and experimental studies in a developmental sense (Morisse, 2015), whereas financial economics focused on issues around regulation, cybercrime, and efficiency (Corbet et al., 2019). For its part, social science research on cryptocurrencies initially focused on themes of identity, materiality, and discourse (for example, see Maurer, Nelms and Swartz, 2013; Dodd, 2018). Notwithstanding some early critical voices (Maurer et al. 2013), the end of this speculative phase and the collapse of crypto asset values around Christmas 2017 initiated a more crypto-critical paradigm. Hype was replaced with disillusionment (Kelly, 2019). Bitcoin is not simply 'out there' on the fringes of finance but related to and dependent on the very institutions it seeks to avoid. Swartz (2018: 623) describes this as a form of "infrastructural mutualism".

Cryptocurrencies' underlying technology, the blockchain, was imagined by many to become a game changer for organising business activity and society at large (Nelms, Maurer, Swartz and Mainwaring, 2018: 22). Scott, Loonam and Kumar (2017: 426) note the importance of the distributed ledger - collectively maintained by participating actors - in paving the way for "distributed collaborative organizations"; technology-driven solutions to counter weak state institutions. Central to these new forms of organising is the ambition to substitute the third party, the intermediary, with an intermediating technology (Nelms et al., 2018: 21); to replace traditional trust-based interactions with "trustless" systems permissioned by formal technical rules, and "freed from politics" associated with government regulation, clearing houses, and other financial intermediaries (Scott et al., 2017: 426). But this apparently "apolitical" character of cryptocurrencies is increasingly being questioned (Swartz, 2018: 630). Commentators note a newly emergent technology-based form of politics, which may not initially be recognised as 'political' but nevertheless remains so (Nelms et al., 2018: 24). Drawing out these politics, Baldwin (2018) notes how the crypto-fetish conceals a "traditional consolidation of power and capital ... co-opted and colonised by capital". Going further, Scott (2016) links the rise of cryptocurrencies to a "techno-Libertarian Evangelism" whose role is to provide a new means of converting developing countries to free-market ideologies. The notion of an apolitical and decentralised blockchain becomes more clearly politicised through the ongoing "recentralization around closed payment communities" (Nelms et al., 2018: 26f.), which are not subject to democratic politics but firmly controlled by startups or tech-firms and governed by end-user and terms of service agreements. In short, 'crypto' is ideology-driven and political, promoting private governance over democratic institutions. The idealists' quest for freedom from government regulation of moneys has been captured by techno-libertarian visions for private or privately regulated currencies.

It is in this context that Facebook's proposed cryptocurrency must be understood. Libra proclaims that once freed from state intervention and using a decentralised blockchain, it will "empower billions of people" and lift them out of poverty (LWP, 2019a). And the price of this 
seemingly altruistic gesture? Libra has you believe it will be inexpensive. All they ask for is free reign to develop a new global currency. But it's true cost is hidden, for access to Libra - the right to govern Libra and to participate in the Libra blockchain - is determined exclusively by the Libra Association. The proposed organisation of Libra therefore amounts to a power grab by Silicon Valley elites and allies. It is not simply the technology we should worry about, but rather Libra as a private organisation that seeks to avoid government scrutiny.

In this essay, I examine the Libra offering based on two documents: the Libra White Paper and the Libra Association document (hereafter 'LWP' and 'LAD' respectively). Its announcement on June 18, 2019, was met by considerable public and regulatory scrutiny. But critiques have typically been more concerned with Libra as 'technology' and less so with how actors organise around it. My analysis, therefore, centres on the organisation of the Libra currency in order to reveal how Facebook and the Libra Association imagine the future of payments. ${ }^{1}$ This is a future in which private interests govern payments, allegedly for the good of people around the globe, yet in a way - and this is crucial - that circumvents governmental oversight and intervention.

The dynamic at play here recalls the one outlined by Marilyn Strathern in her 1996 article "Cutting the network". What is presented as an open, inclusive, and democratic proposal to organise a global digital currency is, in reality, opposing these very principles: cutting "stops the flow" - of things, humans, ideas, and so forth (Strathern, 1996: 522). Networks are no longer endless sets of relations; they are cut by organisation and by ownership. Such is the case with Libra, which emphasises belonging and property simultaneously; membership and the capacity to govern is limited to an exclusive set of actors. The Libra currency is therefore the property of the Libra Association members, making Libra a club of sorts: membership in it equals ownership of it. The network is in this way cut: members are separated from nonmembers, the latter becoming mere consumers in the system. This logic of exclusion and centralisation stands in stark contrast to current understandings of blockchain as 'inclusive' and 'decentralised'.

Owning Libra also affords Libra Association members the exclusive capacity to profit from it economically, as well as politically. In connection with this, I use Michel Serres' (1982) work on the parasite to explore how Libra's organisation enables members to position themselves in such a way as to interrupt existing relations and to divert the flow of resources towards themselves (Brown and Reavey, 2017: 291). Here the parasite is not simply the individual actor but instead assumes a collective form, that is, members engage in collective parasitism of the Libra organisation. And neither is parasitism solely a destructive exercise, but rather, it is constructive, creative, and innovative (Brown and Reavey, 2017: 292).

The remainder of this essay is structured around the broader conceptual theme of 'cutting'. Section one explores Libra as a 'cutting-edge' technology, focusing on how this discourse distracts from the organisation of Libra. Section two then discusses Libra as a club run by and for the members of the Libra Association. Libra's club form provides an effective way of limiting participation to members of the organisation and thereby 'cutting off' outsiders from all governance and decision-making powers. Finally, section three focuses on the ways Libra enables its member-owners to 'take a cut' of any profits generated through the uptake of its currency. In particular, it examines the exclusive opportunities afforded to Libra members to extract value from the Libra ecosystem in the future through rent seeking and innovation. The concluding section reflects on the Libra announcement, and in doing so, stresses the need for future research to focus more closely on how technology is organised, put to work, and how its rewards are distributed. 


\section{Cutting-edge? Libra as organisational not technological novelty}

As a proposal, or more specifically, a 'whitepaper', Libra's authors adopt a literary form made popular during the 2016-19 craze for initial coin offerings, or ICOs. ICOs are proposals for new cryptocurrencies authored to attract investors in such schemes. Libra's whitepaper mirrors the form but departs from the content and intention in one key respect: where cryptocurrency start-up founders issue whitepapers inviting the world to buy in, Libra's authors set some pretty high barriers to participation.

The Libra whitepaper also provides hyperlinks to a constellation of technical papers and other documents. The whitepaper itself is a manifesto for financial inclusion via digital payment. It is thin on substance but replete with the idioms of the financial inclusion assemblage (Schwittay, 2011), that is, the set of actors, technologies, and investments - both affective and economic - proposing digital payment and financial technologies as the solution to global poverty. In its associated imaginary, the financial inclusion assemblage essentially posits a lack of access to banking and other formal financial services as the main barrier to eradicating poverty. Given access to these tools, the poor of the world will propel themselves into an ever-expanding global middle class. The set of discourses associated with this assemblage correctly highlight the higher cost to poor people of simply using money due to higher fees and interest associated with informal money carriers, moneylenders, and other intermediaries like check cashers. But it misdiagnoses the problem as one of access alone, rather than acknowledging structural inequalities and sedimented historical patterns of uneven wealth distribution, government welfare support, and global racism.

That said, Libra's animating documents provide a fascinating window onto how Silicon Valley entrepreneurs and the guardians of the digital platforms structuring so much of contemporary life imagine money, society, inequality, and - most significantly for us organisational forms that support a (not so) novel revenue model. I devote most of my analysis to these organisational forms and their relationship to other models in contemporary capitalism.

First, however, a caveat. Libra's developers deserve credit for having done their homework. The main whitepaper and supplementary papers on Libra's governing association, membership model, technological backbone, and programming language display more than a surface familiarity with the policy and practitioner literature on technology in financial inclusion, with the fact that the poor have to pay more than the well off just to make payments, and crucially for us, with the organisational (rather than technological) challenges involved in creating a global digital payments platform. It is also interesting what is not explicitly stated, or what gets short shrift, which may in the long run prove to be the big story here: the proposal buried in the whitepaper to create a portable universal digital identity - something commentators like Dave Birch of Consult Hyperion have picked up on (Birch, 2014). Such a portable digital identity would indeed be revolutionary, and would hold the potential to be both profoundly democratising as well as profoundly dangerous in the hands of an authoritarian state.

Second, some brush clearing. Libra is not a cryptocurrency. At least, not as cryptocurrencies have been defined and put into practice since the advent of Bitcoin in 2009. Unlike Bitcoin, Libra is not maintained and verified by a distributed, decentralised network of computers that participate in the process of transaction verification via a competitive process. Instead, it will be controlled and maintained by the Libra Association, a membership-based group with high barriers to entry. In Bitcoin, participants are incentivised to participate by way of a lottery that provides a reward in the form of a native token or currency-equivalent digital 
right to transact. In Libra, by contrast, transactions are not verified by a competitive process but "turn-taking" (Libra Blockchain Document, 2019: 3). Being a node in the Libra network affords one the right to participate in such turn taking. It also, significantly, affords the right to vote in governance decisions, and the right to a claim on future income derived from the system.

The Libra Association is a Swiss-registered non-profit made up of Founding Members and, eventually, the developers say, others. Founding Members - of which in August 2019, there were 28 who had either signed on or submitted letters of intent to do so - have their status by virtue of the Libra Association's rules governing belonging. These rules provide various member evaluation criteria (Libra Membership Document, 2020: 3), such as:

Making an investment of at least 10 million USD in Libra Investment Tokens, which are a separate digital token from Libra itself, guaranteeing members a share of the eventual profits to be made from the scheme via interest on the reserves held backing the Libra digital token 1:1 in a basket of the world's reserve currencies;

Having more than 1 billion USD in market value or greater than 500 million USD customer balances;

Reaching more than 20 million people a year, "multinationally";

Being on the Fortune 500 or a similar list;

Or being a crypto-focused entity with at least 1 billion USD in assets under management.

Academic institutions can participate, too, if they are on the QS World University Rankings Top 100 and/or have a top-100 computer science department. The possible inclusion of academic institutions lends legitimacy and a research-oriented veneer. It also provides a potential source of new innovations to be built on top of the Libra system, offering additional services besides money transfer.

The developers have a commitment to opening up access to Association membership, including a utopian vision that some day, any ordinary user could become a member of the Association. The idea seems to be that Libra will over time tend toward something like the similarly utopian, massively distributed and decentralised structure of the Bitcoin network. At the same time, the authors of the technical paper on decentralisation admit that, "as of today we do not believe that there is a proven solution that can deliver the scale, stability, and security needed to support billions of people and transactions across the globe" through a truly open, decentralised system (LWP, 2019a).

So, what is Libra? In effect, it is a digital prepaid token. Users and exchanges will purchase Libra using state-issued currencies. Where Bitcoin is 'mined' when transaction validators are rewarded for their work with new Bitcoin, Libra is 'minted' when people put up state-issued currencies to buy it. An equivalent amount of those state-issued currencies is to be held in a set of custodial institutions - presumably, banks or trust companies - around the world, denominated in a basket of currencies determined by a supermajority (66\%) of the members of the Association. Libra's promoters call this a 'real reserve of assets'. Unlike Bitcoin or other cryptocurrencies, backed, presumably, by nothing, Libra will be backed, 1:1, with 'real' assets. Its promoters analogise this to the gold standard. ${ }^{2}$

Libra is also governed by a new, custom built programming language, called Move. Move is a so-called object-oriented language like Ethereum's Solidity, and it constrains coders and users to a specific data structure so only certain, predetermined functions can be carried out 
on it. In particular, Move is designed to "constrain digital assets to the same properties as physical assets: a resource has a single owner, it can only be spent once, and the creation of new resources is limited" (LWP 2019a: 5). Never mind that physical assets themselves do not work this way. For the creators of Libra, property, ownership, and personhood exist in a kind of naturalist realism that separates and stabilises both subjects who can own and assets that can be owned. Ownership is one-to-one, and property has value only insofar as it is backed by something tangible or 'real' that increases in value in direct proportion to its 'limited' supply like gold, in the mythology of the goldbugs. Just as money (for goldbugs) had value because it was backed by real gold in a vault, itself valuable because of its scarcity, Libra will have value based on its backing by reserve currencies, held in banks and similar such vaults around the world.

There is an internal inconsistency, however, in how Libra's authors construe value on this score. Resources are limited, controlled, and constrained. Yet Libra as an asset is to exist in a one-to-one relationship with state-issued currencies. This is somewhat peculiar given the often explicit, anti-'fiat' currency ideology of Libra and the cryptocurrency experiments it aligns itself with (see Golumbia, 2015). Among many Bitcoin proponents and others in the crypto space, state-issued currencies are anything BUT real. They are state fictions, obfuscations from which we must liberate ourselves (libre!). Libra's pragmatic acceptance of them as 'real' stores of value belies its libertarian intent, while its insistence on the 'realness' of real assets and real ownership underscores its ideological commitment to something akin to the gold standard which, in turn, undermines its claims to empowerment and inclusion - for how could all have access if the global store of value is inherently limited?

\section{Cutting off: Libra as a club-run private currency}

There is also a tension in how Libra's authors imagine the class of owners of Libra. There will be owners of the system itself - who have Libra Investment Tokens - and owners of Libra tokens used for payment. The second class of owners would really be mere users, even though Libra's authors put forward the decentralised, democratic vision that one day, these too could become owners of Libra itself: if the system becomes truly decentralised, like the vision of Bitcoin, then Libra would evolve into an open, distributed, 'permissionless' system. This is despite the acknowledgement, quoted above, that the possibility of developing a permissionless system open to any holders of Libra is still not yet 'proven'.

Here is where the organisational structure of Libra starts to matter. The Libra Association bears a very close family resemblance to other cooperative associations in the history of payments and finance. Indeed, it's hard to imagine that its developers did not consult with or at least read the writings of Visa's founder, Dee Hock. Hock spearheaded the effort to create National BankAmericard Incorporated (NBI), the precursor to the Visa network. His chief insight was that the problem facing interbank payments was not technological but organisational. He advocated for an organisational structure that allowed participating banks simultaneously to compete with one another and cooperate to maintain the system. In this way, he envisioned a "genetic code" (Hock, 2005: 108) for a new type of self-organising organisation (Stearns, 2011: 46). One of his core principles was to redefine ownership as "irrevocable rights of participation, rather than stock" which could be "acquired by application and acceptance of membership" (Stearns, 2011: 47).

There are many similarities between the Libra Association and NBI/Visa. Hock imagined that one day, Visa would encompass not just banks but also merchants and even everyday cardholders, in a vast, global distributed system for facilitating the transit of electronic value. 
But Libra takes Hock's principles and turns them inside out. The Libra Association will be participant led, but membership comes through ownership, and affords control. Participants in the Association must make an investment in order to become members. In its original formulation, Visa was not owned by anyone. Where Hock's vision allowed participants to compete with one another while maintaining an overall framework, Libra guarantees its members a share of the collective profit, proportionate to each members' investment. Where Hock's system provided for "power and function [to be] distributive, with no power vested in or function performed by any part" (Stearns, 2011: 47) that could be done by any other part, Libra vests power in voting rights. And votes are in a one-to-one with investment stake (at least for "today", \$10 million a vote; LAD, 2019a: 4). Since participation is limited only to the most highly capitalised participants in the system, governance is thereby (re-) centralised. This is not distributive so much as plutocratic.

Thus, what Facebook and its allies are selling as an open, democratic organisation is, in my opinion, an exclusive club. Alongside the focus on Libra as technology, the democratic principles attested to by the Libra Association are a front behind which to hide the true governance and organisational set-up of Libra. My reading of the club here does not follow its economic interpretation as "co-operative membership" following Buchanan's (1965) seminal work, but rather speaks to the organisation more generally. To illustrate this point, let us take a brief detour to seventeenth-century Scotland.

As Halliday (1966: 146) observes in his study of the Scottish Club movement, club organisation was pivotal to achieving its stated aim of transforming monarchical power structures into parliamentary ones: "A powerful faction had to be created; it had then to be kept united, and, being united, had to be guided into worthwhile activities". Presumably, these worthwhile activities were consensus driven, at least initially, as membership of the faction was aligned to the cause. However, Halliday notes that the emergence and discipline of the club distorted common interests within parliament as members voting on "the merits of each issue [were] overcome by the Club's voting strength" (Halliday, 1966: 147). Ultimately, the Club's power came from its internal cohesion, homogeneity, and the clubbing together around a specific outcome. Decisions were made in private, only to be disclosed to outsiders at the instance of enactment. This tactical manoeuvring worked to force opposition from the outside into a defensive mode.

This may sound like an obscure, unrelated historical anecdote, but it does actually bear some resemblance to an aspect of the Association and its workings, based on my interpretation of what is and, crucially, what is NOT being said in the White Paper. Libra's announcement did not just declare an idea, but also came with a set of documents outlining operations and governing functions in meticulous detail. It appeared ready, well thought through, almost complete. As such, it put the outside world in defence mode. Attacked by critics and put through congressional hearings, there are still many details that remain undisclosed to the public at large (Omarova and Steele, 2019).

Libra as a club unites a particular set of economic actors strategically. Recruitment into the Libra club is private and, therefore, the overwhelming majority of members are likely to espouse similar ideologies favouring neoliberal market governance over public accountability and societal needs. There is no outside interference and no social responsibility (though of course, these characteristics are not advertised). As it appears, the Libra club's intention is strictly economic; however, economic and political power is intrinsically entangled. In particular, the economic interest is served by uniting member interests. All Libra members share a similar and presumably in their view worthwhile goal: to exert private control over a global currency, to exert power over nation states, and to seek rent. 
This is not explicitly communicated by the documents, but clearly implied, and the club is essential in making sense of the Libra proposition organisationally. The Association promises to increase membership from its initial 30 to 100 members, before opening it up to everyone, but as Libra is a private organisation, governments or anyone else have no rights or power to determine who participates in the Club 100; nor can they force Libra to open up the club to everyone. To stave off any unwanted interference, the process of opening-up is to be "determined by the Association Council" (LAD, 2019a: 4). The Association is self-organising its activities claiming a democratic approach: all members have one representative in the Council. But it also informs us that it is the Council that has ultimate authority to "elect and remove members to its board" and that the voting power in the council is "proportional to the size of the investment" (LAD, 2019a: 1 and 4).

Enrolling actors, therefore, is in and of itself a political, strategic act. Enrolment here serves a dual purpose: being enrolled - being invited in by those already inside; and enrolling oneself - the individual act of buying into or subscribing to the idea and roles, and thus enacting them in their intended way (Callon, 1986). The very idea that equal access to the Libra club is 'granted' to anyone and everyone is misguided. Not everyone matters in the same way and only a select few actors will advance the networks' interest.

Setting aside the user/consumer, it does seem unlikely that Libra would actively recruit actors who may ultimately, but foreseeably, be a source of conflict. Within the currency and cryptocurrency context, Libra has approached private payment rails (PayPal, PayU, Visa, Mastercard, and Stripe) but it has not enrolled any public providers of currency (central banks, governments, and so on). ${ }^{3}$ Thus, enrolment or becoming part of the club is predetermined by interessement: the actions taken to "impose and stabilize" the network and to "define the identity, the goals or the inclinations of their allies" (Callon, 1986: 8). Interests impose and order, define and enforce a particular set of relations that ultimately influences and structures action (Callon and Law, 1982). Through this process, Libra shields itself from enrolling actors that are not committed to the ONE imagination of Libra set out by the club.

Democratic principles are in theory easily overridden by the Libra council, which holds 'ultimate power'. Technically voting power is linked to stakes (limited to 1\%) but excess votes above a 1\% stake will be made available to the Board "for delegation" (LAD, 2019a: 4). This may quickly give rise to dominant interests and factions who can make ultimate decisions about the future of the network resting in the hand of the council by a simple majority (only "the most important [decisions require] a greater than two-thirds supermajority" [LAD, 2019a: 3]). This is not so much democratic, but rather suits the idea of the club in a traditional club theory sense, insofar as "coordination and cooperation require dominant providers" (Fratianni and Pattison, 2001: 334). The existence of dominant interests questions the notion of club members as homogenous crowds (in their decision-making capacity, not character) and instils a de facto hierarchy of the club (Sandler and Tschirhart, 1997: 351).

This hierarchical structure illuminates who has power over Libra: members are represented in the council, council elects board, and the board rules over Libra. Democracy, in its hierarchical form, is cut by membership. This is an active process, with the act of cutting built into the club: first, through posing restrictions on who can be a member, such as with the 'validator node' requirement (a function that requires technical prowess and thus is in itself exclusionary); and second, by outright refusal of membership. The latter is not discussed in the document, but it also does not state that any organisation fulfilling the criteria has a right to join. The Council also keeps the option to "remove Founding Members" (LAD, 2019a: 5), but it does not speak to removing non-founding members of the association in the future. What constitutes "permissible" actions by members, council, and board is left open to change. 
The LAD (2019a: 4) stresses that "related entities [will be prevented] from presenting themselves as two distinct" actors in the network, arguably to alleviate concerns about the relationship between Calibra and Facebook itself. It also further underlines the narrative that diverse interests are represented at association level, including those of "Nonprofit and Multilateral Organizations, and Academic Institutions". But as it turns out, most of these actors (especially after the recent departure of payment rails) are highly interconnected. Elise Thomas' 2019 Wired article illustrates the intricate linkages - investment, executive, partner, board membership, and so on - across these actors. This even includes those members that are intended to spearhead Libra's social impact advisory board; social impact will undoubtedly be redefined in their image. Again, this reiterates the concentration of power in club members, and crucially, the Silicon Valley elite. None of this corresponds with claims of transparent decision-making, financial inclusion, or accountable and proper governance (LAD, 2019a).

These practices of cutting the network recall Marilyn Strathern's push back against the idea of actor-networks as infinite, ever expanding, and all encompassing. In her 1996 article, Strathern demonstrates the finiteness of networks by raising the issue of ownership that cuts the actor-network, its identity, and belonging. She highlights how open networks - chains of research teams building on each other's previous advances - are severed by claims of ownership. The team that has the 'breakthrough', that finds the true innovation, renders any prior advances insignificant. The new 'owners' do not share proceeds across the network, they consume all the rewards themselves.

Libra demonstrates a purposeful cutting of the network through ownership. It is an intentional move to retain control among like-minded actors. The Libra club is set up to be finite. It is characterised by its ability to refuse 'otherness', that is anything or anyone that does not fit in and poses a threat to the club's internal rules and wants through the Libra Council and Board. Guarded by exclusivity, entrance to the club is only afforded to the politically willing and ideologically enrolled.

The initial list of Founding Members appears strongly aligned with libertarian ideas of government 'light' and strong support for private governance. The presence of venture capitalists and the absence of regulated financial entities, banks, fund managers, and so on raises further questions about the qualities and characteristics of those invested and what Libra may become. The Libra club has ultimate power and control over the Libra proposition. But it also has the ultimate power to control Libra's future. Its claim of a diverse membership protects this self-given right in two ways: first, it shields it from unwanted interference, and, second, it provides its members with the control to shape the future in their interest. If Founding Members' past actions are anything to go by, we get a pretty good idea of what that future may bring: control over us and the extraction of rent.

\section{Taking a cut: Power to control, power to seek rent}

By seeing Libra for what it is - not a democratic organisation but a club - we can open up a debate that focuses on the real intentions here. The true potential gain is strictly private and withheld from non-members. Club membership offers a perceived and real net-gain to members extracted from a public good. Crucially, the claim to be of public benefit may not be inconsistent with a claim by the club to extract private rents, but rather, it reveals a problem of distribution as it exposes a tiered existence: participant consumers of Libra on the bottom, those who rule over it on the top. Libra is neither public nor private: it is both.

In many respects, Libra sets up a novel organisation that keeps its future open. There is little tangible evidence for what Libra will look like in 5 or 10 years. And in doing so, Libra 
retains options to morph into otherness so long as two-thirds of Libra Association members vote for it. This includes the opportunity to extract rent, not only to cover costs, but also to seek profits. There are four instances of references to the Libra Investment Token in the initial LAD which clearly establish profit-seeking intentions:

Page 1: "the distribution of dividends to Libra Investment Token investors";

Page 4: "[...] financial return received from the Libra Investment Tokens, which is proportional to the size of the investment";

Page 9: as prime instrument through which investments were meant to be raised via "private placement[s]"; and

Page 10: as key means to "allocate [... surplus] funds for distribution to [...] investors" [emphases added]. ${ }^{4}$

The selling of Libra as an investment opportunity signals a clear for-profit future for Libra, albeit one that is hidden beneath the veneer of financial inclusion and empowering of the world's poor. The terms of these investments are deliberately kept private and the promises made remain shrouded in secrecy. Concealing the terms of future entitlements fixed in these contracts further aligns member interests (Jones, 2014: 56). Libra members are bound to secrecy by this membership and failure to commit would threaten the collective endeavour. Unlike other private offerings - for example CDO offering circulars - these contracts are not accessible to the public (cf. Tischer, Maurer and Leaver, 2019: 560), which raises questions as to how central profitability is to Libra. To what extent does profit become a key performance factor for members and how does this inform strategic decision-making of the Libra Board and Association?

Yet to focus solely on ownership distracts from the true extractive potential within the Libra system organised and operating as an exclusive club. We can frame this future extractive capacity using Michel Serres' concept of the parasite. According to Serres (1982: 37), an organisation is a collection of things and relations. Putting things in relation to each other affords them a function, the power to act in specific ways (Brown and Reavey, 2017: 289): a manager only has power over their workers; a press can only reshape materials that are inserted. Without relation, things lose their function, but not their individual existence. Organisation formalises the relations between things; organisations appear as complete, stable, and orderly. Within this scene, the parasite is the source of change, temporarily destabilising relations between things and creating new orders as a result (Serres, 1982: 38; cf. Brown and Reavey, 2017). The parasite is the 'third' - it creates a new relation within a system that disrupts the existing set of relations and thereby alters the functioning of a system. Importantly for Serres' view of economic development, this parasitism is not negative, but rather foundational to change and progress, through irritation, after which follows a new "reinforced equilibrium, like a sur-equilibrium" (Serres, 1982: 168). As Brown and Reavey (2017: 282) remark, parasitism is "internal to the very functioning of the system". Such an irritation of existing relations - through new technology, new KPIs, new management, or new ideologies - introduces new logics, new senses, and new mobilities into what would otherwise be a static system (Brown, 2013: 89).

What is striking about Libra's self-confessed set-up and organisation is that it invites the parasites in, not through the back door, but through a shiny gate for investors. Of course, we can delineate parasitism to investor owners, or Libra Association members, as has been suggested by Strathern (1996). But in the case of Libra, investors are not simply external 
claimants of surplus profits who, rightly or not, extract resources that could otherwise be put to productive use (Stout, 2012). Libra investors, that is, Libra Association members, are integral to the functioning of Libra, and they have a mandate to decide its future, through irritation and innovation.

Libra's Association is not a neatly bounded private organisation in the traditional sense but multi-layered, interwoven, and entangled. It is a platform, a network, and an infrastructure in a constant state of flux between open and closed. This hybridity is wanted in the case of Libra. Its fixity lies in its demarcation from what is outside of it, the non-investor, the user, the public, and so on. But its internal fluidity, its openness to be re-networked, to expand and contract in terms of actors, is what makes it potentially superior in capturing opportunities to seek rent. Brown and Reavey (2019: 284) call this "endoparasitic criticality" [emphasis in original], an effective form of parasitism that "foster[s] and encourage[s]" disruption, novelty, and innovation through a proactive reordering of relations.

Here we can recognise the collaborative and competitive potential of club actors to shape Libra by altering established relations and constantly adding to Libra's complexity. Stabilising and destabilising Libra - its processes, make-up, and functions - are essential steps to driving Libra and maintaining the parasitic collectivity as a closed loop system (Burton and Tam, 2015: 111). This is not a finite process, but a constantly reconfigured, iterative, and repetitive process that changes the configuration of the holistic object (Libra). Being last is only ever a temporary condition.

The LWP advertises Libra's stability: Libra's "value will remain relatively stable over time" and it will be "a stable digital cryptocurrency" (2019a: 3, 7). However, the Libra organisation will be evolving and creating new opportunities for members to extract rent. Some of these changes will be intended and sanctioned by its members via a supermajority. For example, adjusting the Libra Reserve Policy risk preferences upwards will increase the "interest on the reserve assets [...] used to cover the costs of the system, ensure low transaction fees, [and] pay dividends to investors" (LWPa, 2019: 7, emphasis added). As reserve management will be fully automated (LAD, 2019a: 2), even small adjustments may significantly increase the surplus generated by the Libra Reserve.

Parasites live off their host and consequently the Libra system must be sustainable. Collective decisions to modify or innovate Libra would take into account the risk posed to Libra as technology and organisation. Governance by club is subject to agreement from both Council and Board, and because of this, collective forms of parasitism are likely to favour incremental change and "opportunit[ies] for responsible financial services innovation" (LWPa, 2019: 1) in particular.

Given the involvement of sophisticated financial actors in Libra, it is easy to imagine a broader set of financial innovations taking place, driven by internal parasites. A mundane product at the outset, Libra has the potential to redirect income in various ways. Parasitism may not be confined to Libra club members but may also be external. In fact, even in its first incarnation, Libra 'invites' the third in (Serres, 1982), external parasites that alter and extend relations outwards. The initial Libra documentation notes two cases of third-party involvement: as liquidity providers (LAD, 2019a: 10) and as developers for smart contracts (LWP, 2019a: 10). The point here is not to say that these two functions are necessarily problematic, but rather, that they illustrate openness to 'partnering up' with others.

At this point, it may appear far-fetched to speak about innovating Libra and third-party involvement. However, we should recognise that even mundane products provide considerable scope for financial innovation. For example, the humble mortgage - a safe, long-term asset has been subject to substantial innovations. At the level of the product the emergence of Alt-A 
and Ninja mortgages was a response to shifts in market demand that altered the inherent quality of mortgages. But this risk, rather than being seen as a risk, was imagined as an opportunity to further expand the market through innovation: the adding of CDSs into the mix of already increasingly opaque set of MBSs and CDOs for the benefit of the parasites positioned last. After a short-lived bonanza, the system imploded and almost took with it the global financial system. It is easy to imagine how a privately organised global currency like Libra provides a similar set of opportunities for innovation driven by financial interests and associated third parties. Third-party involvement may thus be understood as an attempt to parasite the Libra ecosystem by gaining technical power to divert income flows to themselves as occupants of the last position in the parasitic chain (Brown, 2013: 93).

\section{Post-scriptum: What is Libra for?}

The announcement of Libra was a peculiar event. Regulators and central banks had already expressed their concerns about Facebook's currency in private conversations. ${ }^{5}$ Moreover, given the various scandals Facebook was embroiled in at the time - Cambridge Analytica, election interference, violations of user privacy, and so on - it seemed unlikely that Libra would be supported by the public either. So, why announce Libra in the first place? And why present Libra as a finalised digital currency with no lesser an aim than to transform money itself?

We can think of the Libra as a provocation; an attempt to explore how the public, the media, and the academy might react to a private currency issued and run by global tech firms and allies. Unsurprisingly, critical voices drove out the supporters. Critiques of Libra encompass both generic social, political, and economic concerns, as well as more specific risks, including those related to national sovereignty, the dominance and interconnectedness of Tech-grandees, Facebook's growing leadership within this cabal, and even the empowerment of Zuckerberg himself (Bokat-Lindell, 2019; Posner, 2019; Thomas, 2019). Seeking to justify its existence as a 'do-gooder' and force for financial inclusion did little to silence these critiques (see Baradaran, 2019).

Nevertheless, there is scant evidence that Libra has abandoned its initial plan or responded to public concerns. The first version of Libra documents "US-1" published with the announcement on June 18,2019, are practically identical to the revised versions dating December 8, 2019 (LAD, 2019b) and January 21, 2020 (LWP, 2020). No announcements were made that fundamentally reverse issues of club membership and the exclusion of governments. Libra remains what Facebook and friends intended it to be all along: a private, exclusive club.

Still, there is one striking omission from the most recent LAD (2019b): NO reference is made to 'investments' or the 'Libra Investment Token'. In the original LAD, the latter was mentioned 19 times. Even the "investment of at least $\$ 10$ million" is now replaced with "commitment of at least \$10million" [emphasis added] (LAD, 2019b).

Why does this matter? It tells us something about how the club responds to concerns around the idea of Libra as a for-profit investment, which Bill Maurer and I briefly raise in our Conversation piece (Maurer and Tischer, 2019). Concealing the fact that profit-seeking investors were at the heart of the Libra offering is problematic.

As it stands, the Libra documents no longer disclose what happens to any surpluses generated in the future. This could mean that investors no longer expect to extract surplus profits. Or it could mean that profitability will no longer feature in the public discourse, and will only be disclosed to parties privy to the club, i.e., investors who gain access to Libra via 
"private placements" (LAD, 2019a: 9). These omissions strengthen the observation that Libra is a private, exclusive club.

Libra was never intended to be the kind of distributed cryptocurrency that was valued by the creators of Bitcoin. Of course, Libra could have been different: it could have been a decentralised, participatory system like Hock envisioned Visa would become (for the record, it didn't; Visa went public in 2016, abandoning many of Hock's principles). But instead, Libra has opted for an organisation that mirrors what Nelms et al. (2018: 26) predicted - a recentralised system controlled by Big Tech and governed by private and technical-legal agreements.

In this regard, the Libra case speaks to the ways in which technologies are put to work by organisations in order to reshape socio-economic structures, behaviours, and outcomes in their favour. Seeing beyond Libra as simply another novel technology allows us to interrogate the organisation of Libra and the inconsistencies arising between claims of Libra as decentralised and publically beneficial vis-à-vis the reality of Libra as concentrating ownership and power amongst like-minded elites. Strathern (1996) and Serres (1982) provide useful conceptual starting points for situating the public versus the private in this debate: ownership cuts the network and members innovate and redirect flows towards themselves. Libra is a private takeover of a public good not simply confined to the creation of a currency, but also as a means to create an entire global infrastructure that exists beyond the reach of conventional government regulation. And this is not accidental: basing the Libra Association in Switzerland protects Libra from being subjected to any external supervisory authority. It is the members of this club who are tasked with overseeing Libra's "evolving [...] ecosystem" (LWP, 2019a: 3). Future research into Libra and other technology-based organisations must not be distracted by the complexity of the intermediating technology, but instead, should focus on how this technology is organised, put to work, and how its rewards are distributed.

\section{Acknowledgments}

I would like to thank Bill Maurer for prompting this research into Libra, for his early contributions to this endeavour, and for the many helpful comments he provided throughout. Thanks as well to the attendees of the Finance and Society Network conference in London, 1213 December 2019, and to Dean Pierides, who always challenges my ideas and provides direction. Lastly, thanks to Amin Samman for providing editorial guidance and comments throughout the process.

\section{Notes}

1. The Libra Association includes a consortium of actors from payments, global tech, blockchain, venture capital, and other business sectors. However, since inception, Facebook remains the key proponent, and other founding members have either remained silent or since left the Association.

2. People new to thinking about money, or who think money is a problem that can be fixed with a technological solution, often imagine money in terms of the gold standard. It is still always a surprise for many people to learn that money today is not backed by gold. The actual history of the gold standard is always glossed over, to say nothing of what going back onto the gold standard would do to modern economies. It bears pointing out that the gold standard supported the interests of lenders against borrowers; led to deflation; prompted imperial wars; and was subject to just as much political manipulation as the much maligned 'fiat' currencies governing world markets today.

3. Most of these, bar PayU, have since quit the project, and recently the MasterCard CEO has given 
concerns about compliance, fungibility, and the broader business model as reasons for his company's departure (see Armstrong, 2020).

4. In one instance, the original Libra White Paper makes reference to "pay[ing] dividends to investors who provided capital to jumpstart the ecosystem" (LWP, 2019a: 7). However, this was removed in an early revised version published on 23 July 2019 (LWP, 2019b).

5. Jerome Powell, Chairman of the Federal Reserve, in replying to a question from the floor, confirmed that Libra was discussed with regulators and central banks prior to its announcement in June 2019: "You know Facebook, I believe, has made quite broad rounds in the ... around the world with regulators, supervisors and lots of people to discuss their plans and that, that certainly includes us". Available at: <https://www.youtube.com/watch?v=67o-Nu4zCVQ/>, from 29:57min

\section{References}

Armstrong, R. (2020) Mastercard chief speaks out against nationalism and Facebook. Financial Times, 3 February.

Baldwin, J. (2018) In digital we trust: Bitcoin discourse, digital currencies, and decentralized network fetishism. Palgrave Communications, 4(14): 1-10.

Baradran, S. (2019) Facebook's cryptocurrency won't help the poor access banks. Here's what would. Washington Post, 29 October.

Birch, D. (2014) Identity is the New Money. London: London Publishing Partnership.

Bokat-Lindell, S. (2019) Can we trust Facebook to run a bank? New York Times, 24 October.

Brown, S.D. (2013) In praise of the parasite: The dark organizational theory of Michel Serres. Informática na Educação: Teoria e Prática, 16(1): 83-100.

Brown, S.D. and Reavey, P. (2017) Dark organizational theory. Journal of Cultural Economy, 10(3): 28095.

Buchanan, J.M. (1965) An economic theory of clubs. Economica, 32(12): 1-14.

Burton, J. and Tam, D. (2015) Towards a parasitic ethics. Theory, Culture \& Society, 33(4): 103-25.

Callon, M. (1986) Some elements of a sociology of translation: Domestication of the scallops and the fishermen of St Brieuc Bay. In: Law, J. (ed.) Power, Action and Belief: A New Sociology of Knowledge? London: Routledge, 196-223.

Callon, M. and Law, J. (1982) On interests and their transformation: Enrolment and counter-enrolment. Social Studies of Science, 12(4): 615-25.

Corbet, S., Lucey, B., Urquhart, A. and Yarovaya, L. (2019) Cryptocurrencies as a financial asset: A systematic analysis. International Review of Financial Analysis, 62(March): 182-99.

Dodd, N. (2018) The social life of Bitcoin. Theory, Culture \& Society, 35(3): 35-56.

Fratianni, M. and Pattison, J. (2001) International organisations in a world of regional trade agreements: Lessons from club theory. The World Economy, 24(3): 333-58.

Golumbia, D. (2015) Bitcoin as politics: Distributed right-wing extremism. In: Lovink, G., Tkacz, N. and de Vries, P. (eds.) Moneylab Reader: An Intervention in Digital Economy. Amsterdam: Institute of Network Cultures, 117-31.

Halliday, J. (1966) The club and the revolution in Scotland 1689-90. The Scottish Historical Review, 45(140): 143-59.

Hock, D. (2005) One from Many: VISA and the Rise of Chaordic Organization. San Francisco, CA: Berett-Koehler Publishers.

Jones, G.M. (2014) Secrecy. Annual Review of Anthropology, 43: 53-60.

Kelly, J. (2019) Blockchain: Disillusionment descends on fiancial services. Financial Times, 24 September. 
LAD (2019a) The Libra Association. Document Version US-1. Downloaded: 6 July 2019.

LAD (2019b) The Libra Association. Document Version US-Rev0812. Downloaded: 12 February 2020.

Libra Blockchain Document (2019) The Libra Blockchain. Document dated 25 June 2019. Available at: <https://developers.libra.org/docs/assets/papers/the-libra-blockchain/2019-06-25.pdf/>. Accessed 15 February 2020.

Libra Membership Document (2020) How to Become a Founding Member. Document Version USRevised012120. Downloaded: 23 February 2020.

LWP (2019a) An Introduction to Libra. Document Version US-1. Downloaded: 2 July 2019.

LWP (2019b) An Introduction to Libra. Document Version US-Rev0723. Downloaded: 29 August 2019.

LWP (2020) An Introduction to Libra. Document Version US-Revised012120. Downloaded: 12 February 2020.

Maurer, B., Nelms, T. and Swartz, L. (2013) 'When perhaps the real problem is money itself!' The practical materiality of Bitcoin. Social Semiotics, 23(2): 261-77.

Maurer, B. and Tischer, D. (2019) Facebook's Libra: It's not the 'crypto' that's the issue, it's the organisation behind it. The Conversation, 6 August. Available at: < https://theconversation.com/ facebooks-libra-its-not-the-crypto-thats-the-issue-its-the-organisation-behind-it-121223/>. Accessed 15 February 2020.

Morisse, M. (2015) Cryptocurrencies and Bitcoin: Charting the research landscape. Presented at the 21st Americas Conference on Information Systems, Puerto Rico. Available at: <https:// pdfs.semanticscholar.org/0835/a6fc11f34710d2622bf4ee306c66f5150da9.pdf/>. Accessed 15 February 2020.

Nelms, T.C., Maurer, B., Swartz, L. and Mainwaring, S. (2018) Social payments: innovation, trust, Bitcoin, and the sharing economy. Theory, Culture \& Society, 35(3): 13-33.

Omarova, S. and Steele, G. (2019) There's a lot we still don't know about Libra. New York Times, 4 November.

Posner, E. (2019) The trouble starts if Facebook's new currency succeeds. The Atlantic, 26 June. Sandler, T. and Tschirhart, J. (1997) Club theory: Thirty years later. Public Choice, 93(3/4): 335-55.

Schwittay, A. (2011) The financial inclusion assemblage: Subjects, technics, rationalities. Critique of Anthropology, 31(4): 381-401.

Scott, B. (2016) How can cryptocurrency and blockchain technology play a role in building social and solidarity finance? UNRISD Working Paper 2016-1, February: 1-25.

Scott, B., Loonam, J., and Kumar, V. (2017) Exploring the rise of blockchain technology: Towards distributed collaborative organizations. Strategic Change, 26(5), 423-428.

Serres, M. (1982) The Parasite. Baltimore, MD: Johns Hopkins University Press.

Stearns, D.L. (2011) Electronic Value Exchange: Origins of the VISA Electronic Payment System. London: Springer Verlag.

Stout, L. (2012) The Shareholder Value Myth: How Putting Shareholders First Harms Investors, Corporations, and the Public. San Francisco, CA: Berett-Koehler Publishers.

Strathern, M. (1996) Cutting the network. The Journal of the Royal Anthropological Institute, 2(3): 51735.

Swartz, L. (2018) What was Bitcoin, what will it be? The techno-economic imaginaries of a new money technology. Cultural Studies, 32(4): 623-50.

Thomas, E. (2019) The ties that bind Facebook's Libra. Wired, 10 July.

Tischer, D., Maurer, B. and Leaver, A. (2019) Finance as 'bizarre bazaar': Using documents as a source of ethnographic knowledge. Organization, 26(4): 553-577. 